\title{
Effects of Humidity on the Development of Grapevine Powdery Mildew
}

\author{
J. E. Carroll and W. F. Wilcox
}

Department of Plant Pathology, New York State Agricultural Experiment Station, Cornell University, Geneva 14456.

Current address of J. E. Carroll: New York State IPM Program, New York State Agricultural Experiment Station, Cornell University, Geneva 14456.

Accepted for publication 4 April 2003.

\begin{abstract}
Carroll, J. E., and Wilcox, W. F. 2003. Effects of humidity on the development of grapevine powdery mildew. Phytopathology 93:1137-1144.

The effects of humidity on powdery mildew development on grape seedlings and the germination of Uncinula necator conidia in vitro were examined. Studies were conducted at an optimum temperature of $25 \pm$ $2{ }^{\circ} \mathrm{C}$. Disease on foliage was markedly affected by humidity levels in the test range of 39 to $98 \%$ relative humidity ( $\mathrm{RH})$, corresponding to vapor pressure deficits (VPD) of 1,914 to $61 \mathrm{~Pa}$. Incidence and severity increased with increasing humidity to an optimum near $85 \% \mathrm{RH}$, and then appeared to plateau or decrease marginally at higher values. Conidial

influenced less strongly. There was a strong, positive linear relationship between humidity level and frequency of conidium germination with RH treatments of $\leq 84 \%$. However, germination frequency fell sharply at RH levels above a mean of $87 \%$. All measures of humidity were equally accurate in predicting germination responses; however, VPD was slightly more effective than $\mathrm{RH}$ in accounting for effects on disease development and pathogen sporulation, and both were more effective than absolute humidity. Humidity appears to play a significant role in grapevine powdery mildew epidemiology, confirming the benefits of management practices to avoid and mitigate high humidity in the vineyard canopy.
\end{abstract} density and chain length also were proportional to humidity, but were

Powdery mildew, caused by Uncinula necator (Schw.) Burr., is the most ubiquitously damaging disease of grapevines worldwide, reducing yield, vine growth and vigor, and fruit quality $(13,24$, 25 ). Early reports on grapevine powdery mildew from various international locations included anecdotal observations correlating high disease severity with humid atmospheric conditions, including coastal fog; dull and cloudy weather; poor air drainage in the vineyard, low-lying areas, and areas near river banks; humid weather with little or no rain; and relative humidity $(\mathrm{RH})$ values between 40 and 95\% $(2,11,14,16,27)$. However, in the first experimental examination of this relationship, Delp (12) concluded that there was little to no effect of different humidity treatments on either the germination of $U$. necator conidia or the development of primary and secondary hyphae on leaves. In contrast, Mane et al. (21) studied powdery mildew development in irrigated compartments in a vineyard in India and found the rate of disease multiplication to be zero both below $53 \% \mathrm{RH}$ and at $100 \% \mathrm{RH}$. Similarly, Kast (18) developed a system for timing fungicide sprays in German vineyards based, among other things, on a threshold level of 60 to $70 \%$ RH for "humid hours" favoring disease development, although he presented no data in support of these specific values. In contrast, the University of California (UC) Davis powdery mildew risk index, recently developed for guiding disease management programs in California vineyards, has not utilized humidity as a determining variable (15). Yarwood (30) considered most powdery mildews to be very tolerant of low humidity and reasoned that high humidity did not favor their development.

Due to the importance of managing powdery mildew in grape production and the sparse yet conflicting data concerning the role of humidity in its epidemiology, the present study was undertaken to determine the effects of this variable on (i) the incidence and

Corresponding author: J. E. Carroll; E-mail address: jec3@ cornell.edu

Publication no. P-2003-0721-02R

(C) 2003 The American Phytopathological Society
Additional keywords: microclimates, Vitis vinifera. severity of the disease on grape foliage, (ii) pathogen sporulation from infected tissue, and (iii) conidial germination. Brief portions of this work have been published previously $(7,8)$.

\section{MATERIALS AND METHODS}

Humidity control and measurement. Saturated salt solutions, prepared as described in Winston and Bates (29) and in Windholz et al. (28), were used to deliver the specific humidity treatments (Table 1), employing a modification of the technique described by Koball et al. (19) (Fig. 1). For each humidity treatment, a Silencer 55R aquarium air pump (Penn-Plax Plastics, Garden City, NY), with $3.2 \mathrm{~J} / \mathrm{s}$ capacity and set on maximum airflow, was used to move air through the system. Air traveled from the pumps through aquarium air tubing into a 1-liter Erlenmeyer flask containing either distilled water or the appropriate salt solution (for treatments with theoretical humidities above or below the ambient $\mathrm{RH}$ of $50 \%$, respectively). Then, the air continued through aquarium air tubing into a 2-liter Erlenmeyer flask containing the appropriate saturated salt solution and, via 9.5-mm-diameter clear tygon tubing, into the inlet hole on the treatment chamber lids. Treatment chambers consisted of clear polypropylene boxes $(30.5 \times$ $21.6 \times 12.7 \mathrm{~cm}$ [length $\times$ width $\times$ depth]) covered with airtight snap-on lids (Rubbermaid, Wooster, $\mathrm{OH}$ ), which were fitted with Plexiglas windows $(15 \times 25 \mathrm{~cm})$ to allow light entry. Finally, air exited through a 2-cm-diameter outlet hole, covered with one layer of KimWipe (Kimberly-Clark, Roswell, GA), in the opposite corner of the chamber lids. Air was bubbled through all solutions using aquarium air stones. Excess salt was present in each saturated salt solution at approximately $50 \%$ of the solution's volume to prevent exhaustion of the solid phase during the experiment.

A HOBO Pro Series Temp/RH datalogger (Onset Computer Corp., Bourne, MA) was fastened to the lid inside each treatment chamber at the start of all experiments. Dataloggers were set to record temperature ( $T$, degrees Celsius), absolute humidity ( $\mathrm{AH}$, grams per cubic meter), and relative humidity (RH, percent) at hourly intervals. The accuracy ratings of the dataloggers were 
$\pm 0.2^{\circ} \mathrm{C}$ and $\pm 3 \% \mathrm{RH}( \pm 4 \%$ in condensing environments) and $\pm 3 \%$ additional reversible drift when average RH was $>70 \%$. Data were downloaded into a computer at the end of each experiment. Vapor pressure deficit (VPD), i.e., saturation vapor pressure $\left(e_{s}\right)$ minus actual vapor pressure $(e)$, was calculated from the $T$ and $\mathrm{RH}$ data, where $e_{s}=610.78 \exp [(17.269 T) /(237.3+T)] \mathrm{Pa}(23)$ and $e=$ $\left(\mathrm{RH} \times e_{s}\right) / 100$. Treatments in which dataloggers malfunctioned were not included in the results.

All experiments were conducted in a walk-in controlled environment room (Environmental Growth Chambers, Chagrin Falls, $\mathrm{OH})$ set at $50 \% \mathrm{RH}$ and $25^{\circ} \mathrm{C}$. A plant shelf supported the humidity delivery apparatus and the treatment chambers. Lighting was supplied by 30 fluorescent and 10 incandescent lamps in the ceiling and 2 fluorescent lamps approximately $5 \mathrm{~cm}$ above each treatment chamber. Lighting was continuous to prevent photoperiodic fluctuations in temperature and related humidity values.

Plant materials and inoculum. Open-pollinated seedlings of Vitis vinifera 'Riesling' were used in all experiments. Seeds were germinated in plastic sieve trays under mist in a greenhouse and planted in sterile plastic cell flats filled with a mixture of soilless potting mix and sand $(3: 1, \mathrm{vol} / \mathrm{vol})$ containing slow-release fertilizer (10-20-5, N-P-K), and flats were covered with plastic domes to prevent desiccation. At the first true leaf stage, seedlings used for growing $U$. necator cultures were transplanted into $5-\mathrm{cm}^{2}$ sterile plastic pots, and seedlings used in humidity experiments were transplanted into individual 50-ml plastic screw-top, conical centrifuge tubes, whose bottom tips were cut off to allow watering. All seedlings were grown in a reach-in growth chamber (Percival, Boone, IA) maintained at $28^{\circ} \mathrm{C}$ day $/ 22^{\circ} \mathrm{C}$ night $(14 \mathrm{~h} / 10 \mathrm{~h})$ in strict isolation from powdery mildew.

Subsequently, seedlings used for growing U. necator inoculum were transplanted at the four- to six-leaf stage into 7.5 -cm-diameter clay pots and maintained in a greenhouse after inoculation in a spore settling tower (method described below) with a mass culture originally obtained from a severely diseased grape cutting in Geneva, NY. These pots were supported and surrounded by sand inside a $15-\mathrm{cm}$-diameter clay pot. Plastic sleeves to contain the inoculum and prevent incidental powdery mildew infections of the culture plants were made from the cylindrical portions of two 3-liter soda bottles taped together; the tops were covered tightly with muslin to allow air circulation and the bottoms were sealed by inserting them into the sand encircling each potted plant. The units were placed in saucers filled with water to provide irrigation. Fresh inoculum of this same culture was maintained by reinoculating new seedlings at 2-week intervals.

In planta experiments. At the four- to five-leaf stage, plants growing in tubes were selected for uniformity of growth and simi- lar sets of plants were grouped for the various humidity treatments. The centrifuge tube caps were securely fastened to the outer surface of each treatment chamber's bottom side, and shoots were inserted into the chambers by passing them through holes drilled through this juncture. Finally, the centrifuge tubes were screwed into the caps so only the shoot portion of each plant was inside the treatment chamber (Fig. 1D), and the holes in the chambers were sealed from the inside with modeling clay around the base of the plants to prevent entry of moisture from the soil and root zone. The centrifuge tubes containing roots and soil stood inside another plastic pan immediately beneath the treatment chambers (Fig. 1F) on a double-layer capillary mat (Fig. 1G) cut from Thermolan Plus cloth (Freudenberg Nonwovens, Durham, NC), which was kept saturated with a layer of distilled water to provide irrigation.

As soon as this process was complete, treatment chambers containing the plants were taken to the greenhouse for inoculation within an enclosed spore-settling tower $(61 \times 76 \times 122 \mathrm{~cm}$ [width $\times$ depth $\times$ height]). Three to four heavily infected leaves from the inoculum seedlings were taped, mildew side down, to the inside of a funnel supported on a bar stand in the center of the tower. The base of the funnel was attached to a source of compressed $\mathrm{CO}_{2}$ via tygon tubing. A 1-s blast of $\mathrm{CO}_{2}$ at $345 \mathrm{kPa}$ dislodged conidia from the leaf surfaces into the air inside the tower, providing a near uniform distribution of spores on the plants as they were allowed to settle for $15 \mathrm{~min}$. Treatment chamber lids were removed just prior to inoculating plants and were replaced immediately thereafter. Temperature inside the tower was monitored during each inoculation and never exceeded $27^{\circ} \mathrm{C}$. To determine the inoculum density (conidia per square centimeter) in each experiment, five glass microscope slides were placed at arbitrary locations inside the settling tower during inoculation and the number of conidia in 10 views was counted at $\times 50$ magnification under a dissecting microscope. Inoculum densities ranged from 72 to 651 (mean $=299)$ conidia per $\mathrm{cm}^{2}$, depending on the experiment. For each experiment, all plants were inoculated simultaneously to ensure an equivalent inoculum dose on every plant.

Following inoculation, treatment chambers ( 8 or 10 plants per chamber) were moved to the growth room and attached to the saturated salt solution apparatus. Treatment chambers were checked daily and capillary mats were wetted with distilled water as needed. After 14 days, the experiment was terminated and the chambers were brought to the laboratory. Individual plants were assessed for powdery mildew severity by estimating the percent area infected on each leaf, keeping track of leaf position on the plant. Mean severity ratings were determined from the most severely infected leaf on each of the plants in a treatment. This leaf was carefully

TABLE 1. Theoretical and measured relative humidity (RH) values in experiments examining humidity effects on development of powdery mildew and Uncinula necator

\begin{tabular}{|c|c|c|c|c|c|}
\hline \multirow[b]{2}{*}{ Salt } & \multirow[b]{2}{*}{ Theoretical RH (\%)a } & \multicolumn{2}{|c|}{ In planta } & \multicolumn{2}{|c|}{ Conidium germination } \\
\hline & & $n^{\mathrm{b}}$ & Measured RH $(\%)(\mathrm{CV})^{\mathrm{c}}$ & $n$ & Measured RH $(\%)^{\mathrm{d}}$ \\
\hline None $\left(\mathrm{dH}_{2} \mathrm{O}\right)$ & 100.0 & $\ldots{ }^{e}$ & $\ldots$ & 2 & $93.7 \& 96.1$ \\
\hline $\mathrm{K}_{2} \mathrm{SO}_{4}$ & 97.4 & $\ldots$ & $\ldots$ & 4 & $94.0-94.7$ \\
\hline $\mathrm{CaHPO}_{4} \cdot 2 \mathrm{H}_{2} \mathrm{O}$ & 97.0 & $\ldots$ & $\ldots$ & 1 & 91.6 \\
\hline $\mathrm{KH}_{2} \mathrm{PO}_{4}$ & 96.0 & $\ldots$ & $\ldots$ & 4 & $92.8-95.3$ \\
\hline $\mathrm{KNO}_{3}$ & 92.5 & 2 & $89.6 \& 90.1(1.1 \& 1.3)$ & 4 & $90.3-93.7$ \\
\hline $\mathrm{KCl}$ & 85.0 & 6 & $83.0-95.3(0.5-2.5)$ & 4 & $83.4-84.1$ \\
\hline $\mathrm{NaCl}$ & 75.5 & 4 & $85.1-96.4(0.9-1.8)$ & 7 & $73.5-77.4$ \\
\hline $\mathrm{Ca}\left(\mathrm{NO}_{3}\right)_{2} \cdot 4 \mathrm{H}_{2} \mathrm{O}$ & 50.5 & 7 & $61.3-98.1(2.0-9.7)$ & 8 & $51.8-54.4$ \\
\hline $\mathrm{MgCl}_{2} \cdot 6 \mathrm{H}_{2} \mathrm{O}$ & 32.5 & 6 & $39.2-74.3(2.7-12.0)$ & 4 & $31.5-33.6$ \\
\hline $\mathrm{CaCl}_{2} \cdot 2 \mathrm{H}_{2} \mathrm{O}$ & 29.5 & 3 & $58.1-86.2(4.9-18.2)$ & 4 & $28.9-31.4$ \\
\hline $\mathrm{LiCl} \cdot \mathrm{H}_{2} \mathrm{O}$ & 12.0 & 2 & $47.5 \& 56.8(2.3 \& 3.5)$ & 6 & $9.8-10.6$ \\
\hline
\end{tabular}

${ }^{a}$ Theoretical RH delivered by each saturated salt solution at $25^{\circ} \mathrm{C}$.

${ }^{\mathrm{b}}$ Number of experiments in which this salt was used.

${ }^{c}$ Mean values or range of mean values and coefficients of variation measured in experiments assessing powdery mildew development on grape seedlings.

${ }^{\mathrm{d}}$ Mean values or range of mean values measured in experiments assessing germination of $U$. necator conidia in vitro.

e Salt not used in these experiments. 
detached from the plant so as not to disturb the spores and placed on moist filter paper in a glass petri dish, and the number of conidia per chain was counted for each of 10 chains in the area of the most luxuriant mildew growth. Three 5-mm-diameter disks were cut from these regions with a cork borer, and each disk was frozen in a microfuge tube for later quantification of spores. Spores were quantified by adding $0.5 \mathrm{ml}$ of $0.4 \mathrm{M} \mathrm{NaCl}$ plus $0.005 \%$ Tween 20 to the tube, rubbing disks with the tip of a glass Pasteur pipette to free conidia, vortexing at maximum speed for $20 \mathrm{~s}$, and counting the conidia in 10 views on a hemacytometer, and from these values, spore density (conidia per square centimeter) was calculated. Subsequently, the number of conidia on each leaf was estimated by assuming a leaf area of $26 \mathrm{~cm}^{2}$ (the mean value determined in a separate set of measurements) and then integrating the severity and conidial density data for the individual leaves. The experiment was repeated seven times with three to six humidity treatments per experiment. For each dependent variable (severity, incidence, conidia per square centimeter, conidia per leaf, and conidia per chain), the data points within each experiment were standardized to reflect a percentage of the maximum value in that experiment (Table 2), and then these

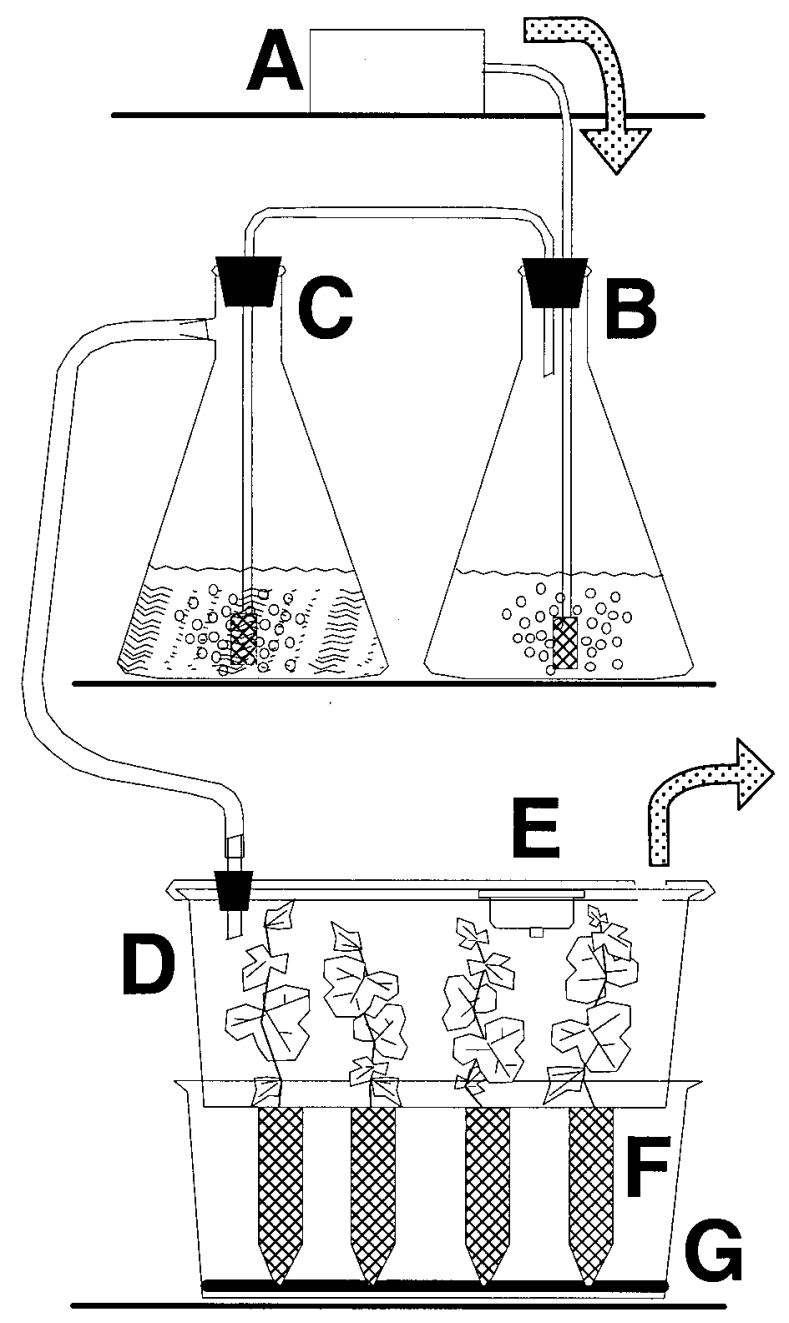

Fig. 1. Schematic representation of the apparatus used to deliver individual humidity treatments. Airflow indicated by dotted, curved arrows. A, Aquarium air pump; B, flask containing either saturated salt solution or distilled water (for treatments below or above the ambient relative humidity $[\mathrm{RH}]$ of $50 \%$, respectively); C, flask containing saturated salt solution; D, treatment chamber, fitted with Plexiglas top, containing shoots of grape seedlings; E, HOBO Pro Series Temp/RH datalogger; F, screw-top conical centrifuge tubes containing soil and roots; and $\mathbf{G}$, double-layer capillary mat for wick irrigation. adjusted values were expressed as a function of the mean value that was measured for each independent variable (RH, VPD, and $\mathrm{AH})$ throughout that experiment. Scatter plots for disease development and pathogen sporulation were modeled to fit trend lines based on the deterministic portion of the variation in the data sets, point by point, using loess locally weighted polynomial regression analysis (10) and S-PLUS software (3.4 Release 1, 1996, Insightful Corp., Seattle, WA).

Conidium germination experiments. Saturated salt solutions in addition to those employed in the in planta experiments were used to expand the experimental humidity range to include both very low levels and those close to saturation. Four experiments examining the effects on conidial germination were conducted at mean RH levels of 10 to $84 \%$; two were run for $24 \mathrm{~h}$ and two for $48 \mathrm{~h}$. Four other experiments were conducted with RH treatments ranging from $10 \%$ to a maximum of 94 or $96 \%$; again, two were run for $24 \mathrm{~h}$ and two for $48 \mathrm{~h}$. Glass coverslips were dusted with conidia in the spore-settling tower, five coverslips were placed into each of the treatment chambers, and the chambers were moved immediately to the growth room where the humidity treatments were imposed, as described previously. At the same time, an additional set of five coverslips not assigned to any treatment chamber was sprayed with $0.5 \%$ cotton blue in lactoglycerine using an artist's airbrush (Preval Model 268; Precision Valve Corp., Yonkers, NY) and each coverslip was inverted onto a microscope slide. These were subsequently examined to determine conidial densities and the background levels of germination present at the start of each experiment. $U$. necator conidia used in these experiments were always derived from colonies initiated 19 to 21 days earlier and were always inoculated onto the coverslips around mid-day.

At the end of the 24- or 48-h experimental periods, coverslips were removed from treatment chambers, sprayed immediately with $0.5 \%$ cotton blue in lactoglycerine, and inverted onto a microscope slide. The frequency of spore germination, defined as occurring when the germ tube length was at least equal to the width of the conidium, was determined at $\times 200$ magnification by examining 200 conidia on each of the five coverslips per treatment. The percent germination attributed to the humidity treatment was calculated after adjusting for the number of pregerminated conidia in the control group at the start of the experiment, which represented from 2 to $52 \%$ of the 1,000 conidia viewed depending on the individual experiment. Data from the spore germination ex-

TABLE 2. Maximum values of measured variables obtained in the seven experiments assessing grapevine powdery mildew development and Uncinula necator sporulation on grape seedlings exposed to different humidity treatments

\begin{tabular}{lccccc}
\hline $\begin{array}{c}\text { Exp. } \\
(\% \text { leaf area })^{\mathrm{a}}\end{array}$ & $\begin{array}{c}\text { Incidence } \\
(\% \text { leaves })^{\mathrm{b}}\end{array}$ & $\begin{array}{c}\text { Conidia/ } \\
\mathrm{cm}^{2}\left(\times 10^{3}\right)^{\mathrm{c}}\end{array}$ & $\begin{array}{c}\text { Conidia/ } \\
\text { leaf }\left(\times 10^{3}\right)^{\mathrm{d}}\end{array}$ & $\begin{array}{c}\text { Conidia/ } \\
\text { chain }^{\mathrm{e}}\end{array}$ \\
\hline 1 & 91.9 & 100.0 & 56.05 & $1,216.09$ & 7.24 \\
2 & 50.6 & 83.3 & 37.05 & 537.11 & 7.06 \\
3 & 75.7 & 90.5 & 46.83 & $1,053.41$ & 7.61 \\
4 & 34.6 & 64.4 & 54.99 & 605.54 & 5.70 \\
5 & 95.6 & 91.9 & 32.59 & 795.87 & 7.35 \\
6 & 46.9 & 38.3 & 34.29 & 469.77 & 7.31 \\
7 & 61.9 & 67.1 & 31.74 & 548.57 & 8.16 \\
\hline
\end{tabular}

${ }^{a}$ Mean percent leaf area infected on the most severely diseased leaf of each plant in an individual treatment chamber.

${ }^{b}$ Mean percent infected leaves on each plant in an individual treatment chamber.

${ }^{c}$ Mean number of conidia per square centimeter of infected leaf surface, based on assays from the most severely infected leaf region on each plant in an individual treatment chamber.

${ }^{\mathrm{d}}$ Mean number of conidia per standard leaf area $\left(26 \mathrm{~cm}^{2}\right)$ as determined by integrating disease severity and conidial density values for each plant in an individual treatment chamber.

${ }^{\mathrm{e}}$ Mean number of conidia per chain, determined for 10 chains within the most severely infected leaf region on each plant in an individual treatment chamber. 

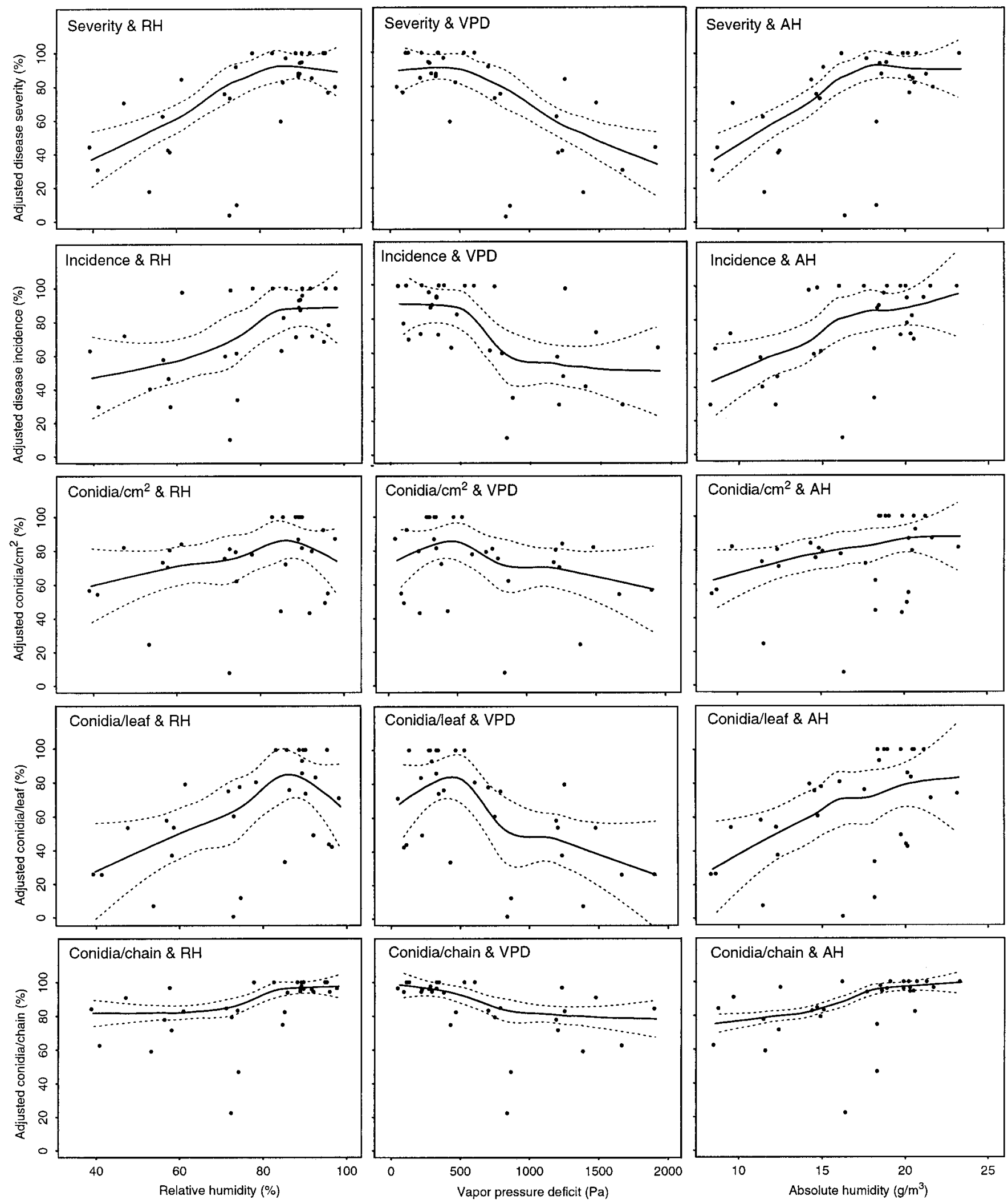

Fig. 2. Scatter plots of results from all seven experiments assessing powdery mildew development and Uncinula necator sporulation on grape seedlings exposed to different humidity levels measured as either relative humidity (RH), vapor pressure deficit (VPD), or absolute humidity (AH). For each measured response, the means within each experiment were standardized to reflect a percentage of the maximum mean value in that experiment, as provided in Table 2. The adjusted values were then plotted as a function of the mean value measured for each independent variable (RH, VPD, and AH) throughout that experiment. Data points were fit to a line using loess locally weighted regression. Dotted lines indicate $95 \%$ confidence intervals. The proportion of variance fit to each line is given in Table 3 . 
periments conducted at $\mathrm{RH} \leq 84 \%$ were analyzed using linear regression; data from experiments that included humidity levels closer to saturation were analyzed using split-line regression and Genstat 5 software (Release 4.1, 1997, NAG Inc., Downers Grove, IL).

\section{RESULTS}

Humidity control. In the in planta experiments, the measured humidity levels were higher than the theoretical levels for virtually all saturated salt solutions used. The magnitude of this deviation and of the variability recorded throughout the 14-day course of each trial was dependent on the salt that was employed. In general, humidities were least variable and closest to theoretical values in treatments designed to produce the highest levels, whereas the converse was true for those intended to produce the lowest levels (Table 1). For instance, for the six experiments utilizing $\mathrm{KCl}$ (theoretical $\mathrm{RH}=85.0 \%$ ), the mean $\mathrm{RH}$ values ranged from 83.0 to $95.3 \%$ with coefficients of variability of 0.5 to $2.5 \%$ in each individual run. However, for the six experiments utilizing $\mathrm{MgCl}_{2}$ (theoretical $\mathrm{RH}=32.5 \%$ ), the mean $\mathrm{RH}$ values ranged from 39.2 to $74.3 \%$ with coefficients of variability of 2.7 to $12.0 \%$ (Table 1). In contrast, humidity levels remained virtually constant in every treatment chamber throughout all eight of the spore germination experiments, with the means of the measured values generally deviating from the theoretical by no more than the precision limits of the instrument (Table 1).

In planta experiments. Disease development was strongly influenced by humidity level (Fig. 2). Compared with humidity expressed as RH, VPD accounted for 19 and $17 \%$ more of the variance in assessed measures of disease incidence and severity, respectively, whereas $\mathrm{AH}$ accounted for 30 and 26\% less (Table 3 ). Conidial density and chain length also were proportional to humidity (or inversely proportional to VPD), with similar relative predictive values among $\mathrm{VPD}, \mathrm{RH}$, and $\mathrm{AH}$; however, these sporulation responses were influenced substantially less by humidity than was disease development (Fig. 2; Table 3). Thus, the strong influence of humidity on the estimated number of conidia produced per leaf (Fig. 2; Table 3) appears to be more a function of its effect on the sporulating area rather than the sporulation density. Measures of disease development and pathogen sporulation were lowest in the lowest humidity treatments and generally increased proportionally to increasing humidity, although some trend lines plateaued or inflected at the highest humidity levels (Fig. 2). Extrapolating from the asymptotes or points of inflection of the trend lines, the optimum humidity levels for U. necator development on grape leaves (at the mean experimental temperature range of 23 to $26^{\circ} \mathrm{C}$ ) were approximately 83.0 to $86.5 \% \mathrm{RH}$, 450 to $520 \mathrm{~Pa} \mathrm{VPD}$, and 18.5 to $\geq 23.4 \mathrm{~g} / \mathrm{m}^{3} \mathrm{AH}$, depending on the measure of disease development or pathogen sporulation (Fig. 2).

Within the range provided, inoculum density had no apparent effect on disease development or pathogen sporulation (data not shown). Average temperature measured throughout the 14-day duration of each individual experiment differed among individual treatment chambers by $<1^{\circ} \mathrm{C}$ in three experiments, $<2^{\circ} \mathrm{C}$ in three experiments, and $<3^{\circ} \mathrm{C}$ in one experiment. The slight variation in temperature among and within the experiments had no significant predictive value for either disease severity or conidia per chain and could account for only $2 \%$ of the variance in disease incidence, $10 \%$ of the variance in sporulation density, and $5 \%$ of the variance in conidia per leaf.

Conidium germination experiments. In experiments in which $\mathrm{RH}$ treatments ranged from 10 to $84 \%$, there was a strong and consistent linear relationship between humidity level and the frequency of conidium germination (Fig. 3). When these values were regressed separately against $\mathrm{RH}, \mathrm{VPD}$, and $\mathrm{AH}$, the slopes of the lines were virtually identical for each independent variable regardless of the time of assessment or run of the experiment (Table 3 ). Furthermore, in both experimental runs in which germination was assessed after $48 \mathrm{~h}$, the coefficients of determination were identical for regressions involving either RH, VPD, or AH. They also were identical in one of the two 24 -h runs and differed only minimally in the other (Table 3). However, in subsequent experiments that also included humidity levels close to saturation, a

TABLE 3. Regression models and parameters for the response to humidity of powdery mildew development in planta and germination of Uncinula necator conidia in vitro

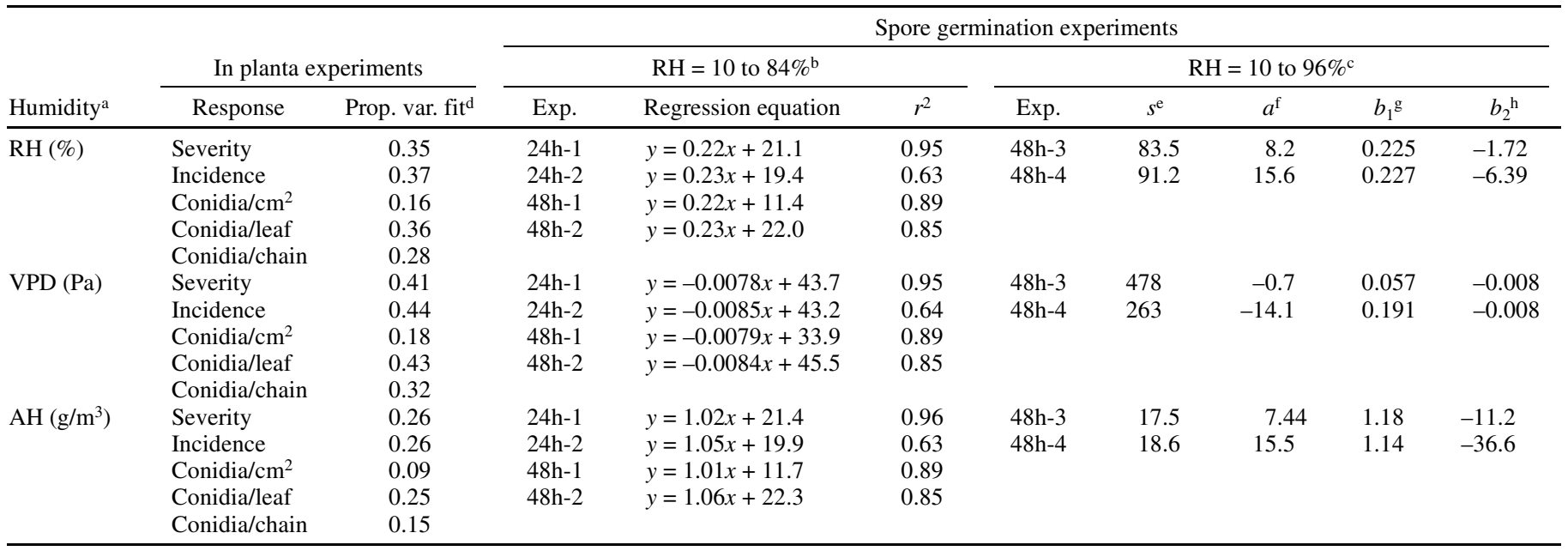

a Humidity expressed as either relative humidity (RH), vapor pressure deficit (VPD), or absolute humidity (AH).

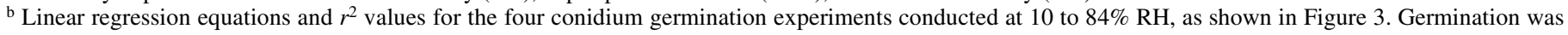
assessed after 24- or 48-h in each of two experiments, respectively.

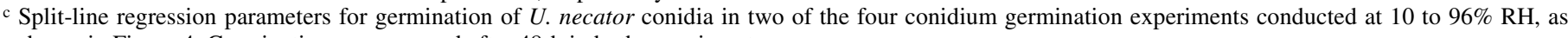
shown in Figure 4. Germination was assessed after 48-h in both experiments.

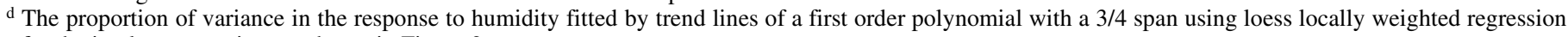
for the in planta experiments shown in Figure 2.

e The split-point in each line.

f The intercept for the first part of the split line.

$\mathrm{g}$ The slope of the first part of the split line.

${ }^{h}$ The slope of the second part of the split line. 
steep drop in germination frequency occurred in the highest humidity treatments in both the 24-h experiments (data not shown) and those extending for $48 \mathrm{~h}$ (Fig. 4). No water condensation was observed on any of these slides, ensuring that reduced germination frequencies were due to high atmospheric humidity rather than free water. Data from the two 48-h assessments were analyzed using split-line regression, where $Y=a+(X \leq s) b_{1} X+(X>s) b_{2} X$, and parameter $s$ represents the split point, $b_{1}$ represents the slope of the first part of the split line, and $b_{2}$ represents the slope of the second part of the split line. The $b_{1}$ slopes for $\mathrm{RH}$ and $\mathrm{AH}$ and the
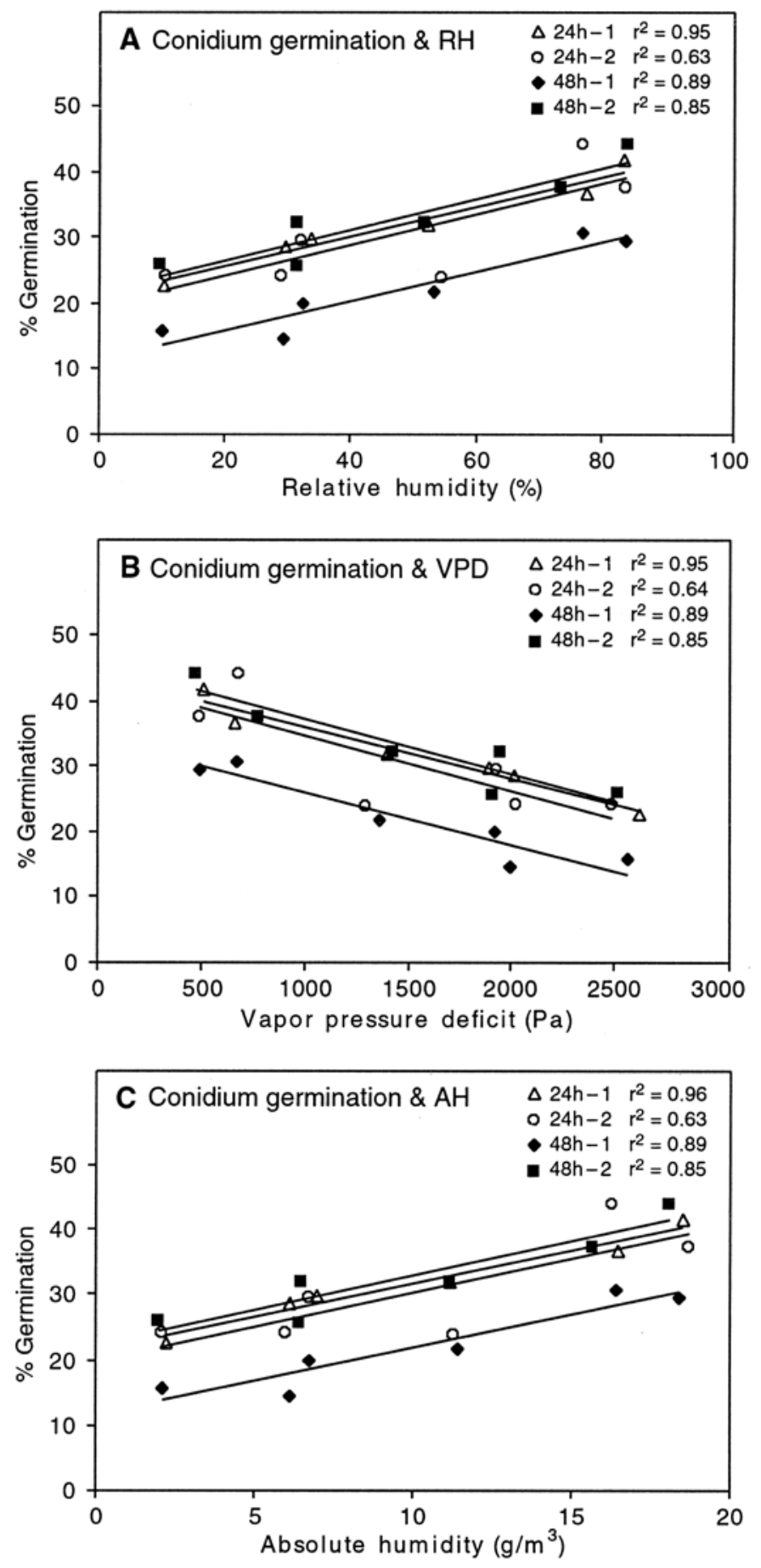

Fig. 3. In vitro germination of Uncinula necator conidia in response to humidity treatments ranging from 10 to $84 \%$ relative humidity (RH). Percent germination was assessed after either 24 or $48 \mathrm{~h}$ in two experiments each and expressed as a function of either A, RH; $\mathbf{B}$, vapor pressure deficit (VPD); or $\mathbf{C}$, absolute humidity (AH). Data were analyzed using linear regression (Table 3). $b_{2}$ slopes for VPD were very similar to the linear regression slopes determined in the previous experiments over similar humidity ranges where the highest levels had not been included (Table 3). The split-point parameter $s$, which gave the theoretical optimum humidity level for spore germination, averaged $87.4 \% \mathrm{RH}, 371 \mathrm{~Pa}$ VPD, and $18.1 \mathrm{~g} / \mathrm{m}^{3} \mathrm{AH}$ for these two experiments (Table 3). Temperature and humidity levels in all treatment chambers remained virtually constant and very close to theoretical throughout the experiments (Table 1).

\section{DISCUSSION}

Over a series of experiments conducted at optimal temperatures, the development of powdery mildew on grape leaves was clearly and markedly affected by humidity levels in the test range of 39 to $98 \% \mathrm{RH}$ (1,914 to $61 \mathrm{~Pa}$ VPD). Although infection occurred at all humidities, both the incidence and severity of disease increased with increasing humidity up to an optimum near $85 \% \mathrm{RH}$, and then appeared to plateau or decrease marginally at higher values. Although consistent with numerous field observations $(2,11,14,16,18,27)$, our data stand in stark contrast to the experimental results of Delp (12), who concluded that humidity
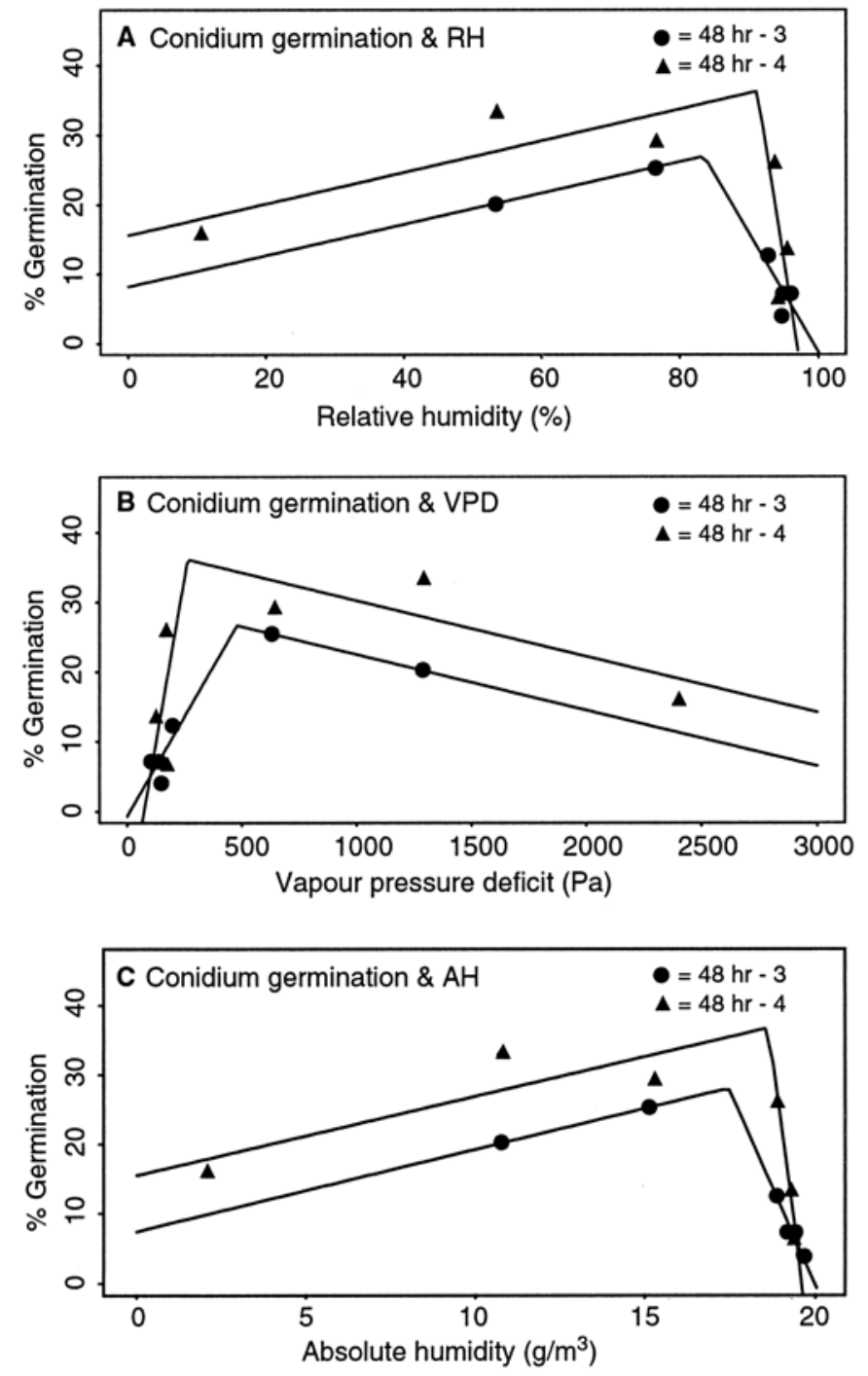

Fig. 4. In vitro germination of Uncinula necator conidia in response to humidity treatments ranging from 10 to $96 \%$ relative humidity (RH). Percent germination was assessed after $48 \mathrm{~h}$ in each of two experiments and expressed as a function of either A, RH; $\mathbf{B}$, vapor pressure deficit (VPD); or $\mathbf{C}$, absolute humidity (AH). Data were analyzed using split line regression (Table 3). 
had "little or no influence" on the development of $U$. necator on grape foliage and speculated that observations to the contrary more likely reflected the preferential occurrence in humid locations of temperatures that were especially favorable for the disease. However, it seems likely that our conflicting results are substantially due to the different methodologies utilized in the two studies, including (i) the range of humidities investigated, i.e., Delp (12) examined only $\mathrm{RH}$ values of $99 \%$ and $\leq 25 \%$; (ii) the incubation times provided between inoculation and disease assessment, i.e., generally $\leq 5$ days for Delp versus our 14 days; and (iii) the techniques used to impose humidity treatments, i.e., Delp utilized a constant source of air at variable temperatures versus our multiple air sources with varying humidities at a near-constant temperature. In addition to the effects on disease development, we also found similar, if less pronounced, effects of humidity on the production of conidia from powdery mildew colonies; however, these were not of the magnitude cited by Bulit and Lafon (5), i.e., a doubling of conidial chain length after $24 \mathrm{~h}$ at 90 to $100 \% \mathrm{RH}$ versus that at 30 to $40 \% \mathrm{RH}$. It is unclear whether such apparent differences merely reflect experiments designed to measure the effect of humidity on sporulation rate versus our experiment designed to measure the effect of humidity on sporulation potential (i.e., our assessments of sporulation were not conducted until approximately 7 days after initial colony appearance). Nevertheless, these data suggest that humidity influences the progress of a powdery mildew epidemic through a multiplicative effect involving both the quantity of infected tissue that develops and the density of conidia produced on it.

The frequency of conidium germination also responded to increases in humidity. Germination increased in a modest but distinctly linear manner from the minimum test level of approximately $10 \% \mathrm{RH}$ to an optimum level of approximately $87 \% \mathrm{RH}$, above which germination frequency dropped sharply. In contrast, Bulit and Lafon (5) cited data showing increased germination at 40 versus $20 \% \mathrm{RH}$, but no significant effect of humidity at $\mathrm{RH}$ levels between 40 and 100\%; however, unavailability of their source material precluded analysis of this conflict with our results. Delp (12) also found no significant effect of humidity on conidium germination at or below the optimum temperatures that we utilized. However, Delp expressed germination frequency as a percentage of that in "check" treatments with 400 to $133 \mathrm{~Pa}$ VPD at either 24 or $27^{\circ} \mathrm{C}$ ( 86 to $95 \%$ or 89 to $96 \% \mathrm{RH}$ ), respectively. These humidity levels are in a range in which germination declined precipitously in our experiments, and it is unclear whether such relative data may have been impacted by suboptimal conditions for germination in Delp's check treatments. In contrast, our results bear some similarity to those of Longrée (20), who found suboptimal germination of Sphaerotheca pannosa (cause of rose powdery mildew) conidia above $99 \%$ and below $95 \% \mathrm{RH}$ at both 21 and $25^{\circ} \mathrm{C}$; however, for $U$. necator conidia the suboptima are lower, i.e., above $91 \%$ and below $84 \%$ RH.

In our study, we were able to maintain a near-constant temperature while varying the levels of humidity, effectively isolating this variable in repeatable experiments. However, the experimental system also had its limitations. For example, initial attempts to utilize a 12-h light/12-h dark illumination regime caused significant diurnal fluctuations in temperature and associated humidity measures within the treatment chambers, forcing the use of continuous light to overcome this problem. Furthermore, we were unable to provide mean $\mathrm{RH}$ levels of $<39 \%$ in the studies examining disease development on grape seedlings, and it was difficult to maintain a constant humidity inside their treatment chambers over the 14-day period of these experiments. The use of seedlings with few relatively small leaves and the separation of moist soil and irrigation water from the treatment chambers were designed to restrict the introduction of extraneous water vapor into them; nevertheless, it appears that the experimental apparatus was unable to fully equilibrate transpirational water vapor, particularly at the lower intended humidities. This conclusion is further supported by (i) observations of increasing humidity within some treatment chambers as experiments progressed (data not shown), and (ii) the ability of the system to maintain virtually constant RH levels very near all theoretical values throughout the conidial germination experiments when plants were absent. It seems likely that the increased precision in humidity control accounts for at least part of the reduced variability in the results obtained in these experiments compared with the in planta studies. However, examining a single response of the pathogen (i.e., conidium germination) rather than the outcome of interactions between the pathogen and multiple host units also would favor reduced variability.

The mechanistic effects of atmospheric humidity on $U$. necator and other powdery mildew fungi are poorly understood. It is possible that high humidity but not free water favors these organisms because they have evolved to utilize water vapor directly. Brodie and Neufeld (4) observed that the conidial protoplast of Erysiphe polygoni shrank only slightly during plasmolysis, suggesting it contains very little free water. Brodie (3) subsequently determined that the apparent osmotic potential of conidial cell sap was $-6,300$ and $-6,800 \mathrm{kPa}$ for E. polygoni and E. graminis f. sp. hordei, respectively, and postulated that such low values might aid the spores in absorbing water directly from the atmosphere. At very low humidities, Clayton (9) found that germ tubes of E. polygoni were short and survived poorly, and Munshi and Singh (22) found that few $U$. necator conidia established successful host-parasite relationships. Kast (18) noted that grapevine powdery mildew is more severe near bodies of water where atmospheric humidities are subject to rapid increases at night, and although this may be related to increased dispersal of conidia under such conditions (6), the effects observed in our experiments occurred in the absence of comparable fluctuations. For biotrophs like the powdery mildew fungi, it also seems plausible that an environmental variable such as atmospheric humidity might affect disease development through an influence on the host and its physiological relationship with the pathogen, although this topic has received little experimental scrutiny. Low humidity favors plant transpiration, which would give rise to a high water vapor flux, favoring directional diffusion of water out of the leaf and out of the powdery mildew mycelium directly (because it is not protected by a cuticle). When interpreting studies of the effects of humidity on powdery mildew development, it should be recognized that humidity in the leaf boundary layer zone inhabited by $U$. necator, i.e., $\leq 500 \mu \mathrm{m}$ above the surface (17), is likely to be higher than that measured in the bulk air, depending on the bulk air humidity and velocity of air movement (26).

It has been argued (1) that VPD is the most meaningful measure of variation in atmospheric humidity when describing its effects on biological systems, including those involving U. necator (12). However, VPD measures were identical to those of $\mathrm{RH}$ in accounting for the effect of humidity in our conidium germination experiments and were only modestly superior to $\mathrm{RH}$ values when analyzing the in planta experiments. Furthermore, measures of VPD are temperature-specific, thus it often is difficult and cumbersome to utilize them in comparing observations or experimental reports obtained at different temperatures. In contrast, measures of $\mathrm{RH}$ allow comparisons of relative water vapor levels across temperatures and are conceptually familiar and easy to interpret. Therefore, to facilitate communication, we have focused our presentation of specific humidity levels in terms of RH measurements; however, we recognize that VPD values may add a modicum of additional precision in some instances and therefore have included these measures for comparison, along with those of AH.

Delp's (12) data suggested that temperature was the only important environmental variable for predicting the development of grapevine powdery mildew, and the current UC Davis risk index focuses solely on temperature with respect to the forecasting of secondary disease cycles (15). From our results, however, it is 
clear that atmospheric humidity also plays a role in multiple phases of this cycle, from the germination of conidia to the development of the resulting colonies on infected tissue and the production of additional conidia therefrom. Our data support Kast's concept of including $\mathrm{RH}$ as a predictive variable in the model he developed for scheduling fungicide sprays in German vineyards (18), though not his designation of $60 \% \mathrm{RH}$ as a minimum for disease development. However, his designation of an optimum level of $\geq 70 \% \mathrm{RH}$ is consistent with our findings of an optimum $\mathrm{RH}$ near $85 \%$. The importance of humidity relative to temperature and the manner in which such information should be applied in disease management programs will most likely need to be elucidated under field conditions in various climatic regions. Nevertheless, viticultural practices designed to minimize humidities within vineyard canopies appear to be prudent components of integrated disease management systems.

\section{ACKNOWLEDGMENTS}

Financial support was provided by USDA Viticulture ConsortiumEast, The New York Wine and Grape Foundation, and Hatch Project NYG-625504. We thank J. Barnard for statistical analyses; F. P. Wong for data used in determining average leaf area; A. N. Lakso for helpful discussions concerning grapevine physiology; and J. A. Burr for technical support.

\section{LITERATURE CITED}

1. Anderson, D. B. 1936. Relative humidity or vapor pressure deficit. Ecology 17:277-282.

2. Bioletti, F. T. 1907. Oidium or powdery mildew of the vine. Calif. Agric. Exp. Stn. Bull. 186:315-350.

3. Brodie, H. J. 1945. Further observations on the mechanism of germination of the conidia of various species of powdery mildew at low humidity. Can. J. Res. 23:198-211.

4. Brodie, H. J., and Neufeld, C. C. 1942. The development and structure of the conidia of Erysiphe polygoni DC and their germination at low humidity. Can. J. Res. 20:41-61.

5. Bulit, J., and Lafon, R. 1978. Powdery mildew of the vine. Pages 525-548 in: The Powdery Mildews. D. M. Spencer, ed. Academic Press, New York.

6. Byrne, J. M., Hausbeck, M. K., and Shaw, B. D. 2000. Factors affecting concentrations of airborne conidia of Oidium sp. among poinsettias in a greenhouse. Plant Dis. 84:1089-1095.

7. Carroll, J. E., and Wilcox, W. F. 2000. The effect of relative humidity on grape powdery mildew development and pathogen sporulation. (Abstr.) Phytopathology 90(suppl.):S12.

8. Carroll, J. E., and Wilcox, W. F. 2002. Effect of humidity on Uncinula necator and grapevine powdery mildew. Pages 44-45 in: Proc. 4th Int. Workshop Powdery Downy Mildew. J. Rumbolz, ed. Department of Plant Pathology, University of California, Davis.
9. Clayton, C. N. 1942. The germination of fungus spores in relation to controlled humidity. Phytopathology 32:921-943.

10. Cleveland, W. S. 1979. Robust locally-weighted regression and smoothing scatter-plots. J. Am. Stat. Assoc. 74:829-836.

11. de Castella, F., and Brittlebank, C. C. 1923. Oidium of the vine. J. Dep. Agric. Victoria Aust. 21:673-745.

12. Delp, C. J. 1954. Effect of temperature and humidity on the grape powdery mildew fungus. Phytopathology 44:615-626.

13. Gadoury, D. M., Seem, R. C., Pearson, R. C., Wilcox, W. F., and Dunst, R. M. 2001. Effects of powdery mildew on vine growth, yield, and quality of concord grapes. Plant Dis. 85:137-140.

14. Gladwin, F. E. 1928. Downy and powdery mildews of the grape and their control. N.Y. State Agric. Exp. Stn. Bull. 560:6-13.

15. Gubler, W. D., Rademacher, M. R., Vasquez, S. J., and Thomas, C. S. 1999. Control of powdery mildew using the UC Davis powdery mildew risk index. APSnet Feature. Published online by The American Phytopathological Society, St. Paul, MN.

16. Jacob, H. E. 1929. Powdery mildew of the grape and its control in California. Calif. Agric. Ext. Serv. Circ. 31.

17. Kapoor, J. N. 1967. Uncinula necator. No. 160 in: Descriptions of Pathogenic Fungi and Bacteria. Commw. Mycol. Inst., Kew, England.

18. Kast, W. K. 1997. A step by step risk analysis (SRA) used for planning sprays against powdery mildew (OiDiag-System). Vitic. Enol. Sci. 52:230-231.

19. Koball, D. C., Wilcox, W. F., and Seem, R. C. 1997. Influence of incubation-period humidity on the development of brown rot blossom blight of sour cherry. Phytopathology 87:42-49.

20. Longree, K. 1939. The effect of temperature and relative humidity on the powdery mildew of roses. Cornell Agric. Exp. Stn. Mem. 223:1-43.

21. Mane, B. S., Khandge, S. V., Varshneya, M. C., and Naidu, T. R. 1996. Role of micro-meteorological parameters on incidence and development of powdery mildew of grapes. J. Maharashtra Agric. Univ. 21:445-449.

22. Munshi, G. D., and Singh, T. 1994. Effect of temperature and relative humidity on the development of Uncinula necator on grapes. Indian J. Mycol. Plant Pathol. 24:179-182.

23. Murray, F. W. 1967. On the computation of saturation vapor pressure. J. Appl. Meteorol. 6:203-204.

24. Pearson, R. C. 1988. Powdery mildew. Pages 9-11 in: Compendium of Grape Diseases. R. C. Pearson and A. C. Goheen, eds. The American Phytopathological Society, St. Paul, MN.

25. Pool, R. M., Pearson, R. C., Wesler, M. J., Lakso, A. N., and Seem, R. C. 1984. Influence of powdery mildew on yield and growth of rosette grapevines. Plant Dis. 68:590-593.

26. Ramsay, J. A., Bulter, C. G., and Sang, J. H. 1938. The humidity gradient at the surface of a transpiring leaf. J. Exp. Biol. 15:255-265.

27. Uppal, B. N., Cheema, G. S., and Kamat, M. N. 1930. Powdery mildew of the grape and its control in Bombay. Bull. Dep. Agric. Bombay 193:130.

28. Windholz, M., Budavari, S., Blumetti, R. F., and Otterbein, E. S. 1983. The Merck Index. 10th ed. Merck \& Co., Rahway, NJ.

29. Winston, P. W., and Bates, D. H. 1960. Saturated solutions for the control of humidity in biological research. Ecology 41:232-237.

30. Yarwood, C. E. 1936. The tolerance of Erysiphe polygoni and certain other powdery mildews to low humidity. Phytopathology 26:845-859. 